Cos

\title{
limiar
}

VOL.1 - $N^{\circ} 1-2^{\circ}$ SEMESTRE 2013

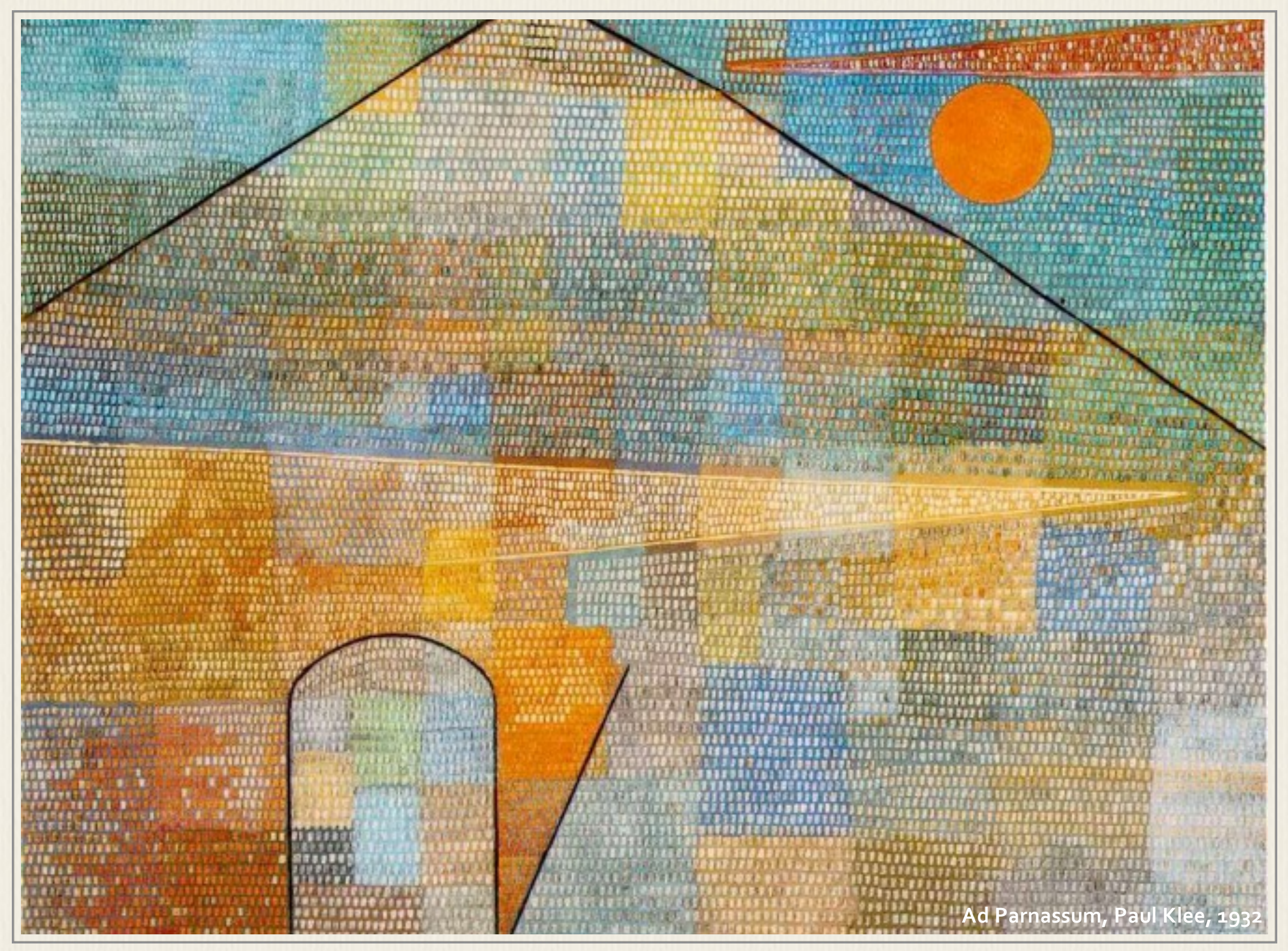




\section{Do modernismo aos anos 60: resistência e criação}

Celso Favaretto

FE|USP

Uma frase de Machado de Assis, a frase final de Iaiá Garcia, "alguma coisa escapa ao naufrágio das ilusões”, serve de emblema para esta tentativa de entendimento da proposta de discussão dos imbricamentos de criatividade e diversidade cultural. Trata-se de propor uma modalidade de análise da produção artístico-cultural brasileira centrada nas expectativas e ilusões de transformação social, articuladas nas ideias e práticas políticas que informaram os projetos e atividades artísticas modernas da década de 1920 aos anos 60. Naquele tempo, foram depositadas muitas esperanças no poder emancipador da cultura: proposições criativas que traduziam nas artes um empenho e fervor poucas vezes experimentado no Brasil. Inscrevendo ideias e ações de resistência, os projetos tiravam sua eficácia da força do desejo que os mobilizava.

Falar, então, de alguns aspectos dos projetos artísticos culturais da nossa modernidade, tirá-los do esquecimento, não entra na chave da nostalgia de um tempo de promessas e entusiasmo histórico e nem na do lamento do que naufragou. Trata-se de falar de projetos que hoje aparecem como ruínas da história mas que no seu tempo catalizaram o sonho e o empenho de transformação, de conjuração da injustiça institucionalizada desde os inícios de nossa história. Revisitar alguns desses projetos, rememorar suas propostas e as modalidades de experiência que motivaram é instrutivo, porque, como se sabe, a memória não transpõe ao presente o que possa ter acontecido, mas redistribui seus objetos, reconstrói os significados e, quando a rememoração não tem apenas poder de evocação, ela permite a rearticulação de signos que um dia forçaram a experiência, o que pode permitir identificar no presente os sintomas de uma outra experiência, indeterminada mas possível. Mas que contudo é preciso configurar e decifrar. Assim, rever os princípios dessas atividades, tendo em vista repontecializá-los segundo as condições presentes do imaginário e da história, não significa simplesmente recodificá-los, resgatá-los, pois esta atitude frequentemente apenas os presentifica com efeitos adaptativos.

Atitude analítica mais adequada para este fim, é a da elaboração, processo de escuta que atravessa as ruínas dos projetos e experiências indagando a possibilidade de outras temporalidades que se abrem para um sentido impressentido. Tematizando-se assim obras, teorias e projetos artístico-culturais daquele tempo das promessas, tem-se em vista configurar estratégias modernas e sondar táticas contemporâneas que compõem um campo de ressonâncias de intensidades que forçam o pensamento, que aguçam nossa sensibilidade para as diferenças. Há uma 
1. Peter Pál Pelbart. Vida Capital. Ensaios de biopolítica. São Paulo: Iluminuras, 2003, p. 142. Cit. de Antonio Negri. Kairós, Alma Venus, multitude. Paris: Calmann-Lévy, 2000. diferença evidente entre a atitude moderna e a algumas ditas pós-modernas no que se refere ao tema da resistência e criação, patentes em atividades artísticas e culturais contemporâneas, que podem ser assim caracterizadas segundo um de seus intérpretes:

Se na modernidade a resistência obedecia a uma matriz dialética, de oposição direta das forças em jogo, com a disputa pelo poder concebido como centro de comando, com os protagonistas polarizados numa exterioridade recíproca mas complementar, o contexto pós-moderno suscita posicionamentos mais oblíquos, diagonais, híbridos, flutuantes. Criam-se outros traçados de conflitualidade, uma nova geometria da vizinhança ou do atrito. Talvez com isso a função da própria negatividade, na política e na cultura, precise ser revista. Como diz Negri: "Para a modernidade, a resistência é uma acumulação de forças contra a exploração que se subjetiva por meio de uma 'tomada de consciência'. Na época pós-moderna, nada disso acontece. A resistência se dá como a difusão de comportamentos resistentes e singulares. Se ela se acumula, ela o faz de maneira extensiva, isto é, pela circulação, pela mobilidade, a fuga, o êxodo, a deserção: trata-se de multidões que resistem de maneira difusa e escapam das gaiolas sempre mais estreitas da miséria e do poder. Não há necessidade de tomada de consciência coletiva para tanto: o sentido da rebelião é endêmico e atravessa cada consciência tornando-a orgulhosa. O efeito do comum, que se atrelou a cada singularidade enquanto qualidade antropológica, consiste precisamente nisso. A rebelião não é pois pontostual nem uniforme: ela percorre ao contrário os espaços do comum e se difunde sob a forma de uma explosão dos comportamentos das singularidades que é impossível conter. É nisso que se pode definir a resistência da multidão". ${ }^{1}$

No processo de construção da modernidade brasileira podem ser assinalados alguns pontos de concentração, de intensificação dos imbricamentos de criatividade e crítica cultural. Lembremos, primeiramente, os anos 20, especialmente o final da década, quando as proposições antropofágicas articularam uma imagem de resistência cultural ainda não conhecida no país, efeito de uma criatividade inovadora que traduzia um imaginário em que os dados e simbolismos etnológicos, antropológicos e estéticos geraram imagens de uma singular concepção de sincretismo cultural que redimensionavam as projeções idealizadas provenientes das vanguardas europeias, fascinadas pelo "amor aos primitivismos". Depois, lembremos os anos 60, quando por retraduções da ênfase modernista no conhecimento do Brasil, o sincretismo foi convertido em tematizações polarizadoras entre o nacionalismo e a internacionalização da cultura, que na criação artística se expressavam na oposição, redutora, entre vanguarda e conformismo. No âmbito das proposições, discussões e criações surgidas do impacto dos dados novos, tal polarização efetuou uma mistura entre os dados do que se denominava na ocasião "cultura popular" - que, embora conceito totalizador supunha vários matizes e compreensões, no fundo pretendia traduzir o essencial da criatividade brasileira - e dados da cultura moderna europeia e da cultura de massa norte-americana. Desta mistura, as artes construíram surpreendentes imagens do país, produzindo uma abertura da sua compreensão jamais antes experimentada. Retomemos pois 
algumas ideias-força desses momentos de ponta, sem entretanto considerar que entre eles nada tenha acontecido. São aqui, apenas, momentos emblemáticos para a discussão que se propõe.

A questão modernista era, fundamentalmente a da brasilidade: conhecer, descobrir, inventar o Brasil. Para isto, as ideias e os processos da vanguarda europeia seriam de muita utilidade. A busca de identidade não deixou de se manifestar como uma espécie de desrecalque com relação à cultura das metrópoles, aqui tomadas desde os tempos coloniais como a cultura a ser imitada - no pensamento, na arte, na arquitetura, nos modos de vida. A aspiração moderna que os anos 20 inauguram aparece, na temática nacional e popular, como "amor aos primitivismos", e como uma "vontade de construção", para a qual muito contribuiu o cubismo que Tarsila, Oswald, Anita, Rego Monteiro e outros exercitaram a partir de Paris. Vontade de construção e nacionalismo, imbricados, definiram, a partir do modernismo, perspectivas de atuação artística e cultural, sendo que somente nos anos 50 e 60 foram radicalizadas segundo um ponto de vista brasileiro, expondo as ambiguidades do processo de modernização, pela exploração crítico-criativa das relações entre modernidade e tradição, centradas em grande parte no importante tema do "encontro cultural".

À medida que se passa da consideração das rupturas modernistas dos anos 20, para o período de construção da modernidade, nos anos 30 e seguintes, em que se dá a consolidação das conquistas modernistas em termos de realização de obras e de institucionalização da produção artístico-cultural, percebe-se que o processo de modernização vinha suprir uma espécie de carência de identidade. Desde os anos 20, em obras como Macunaíma de Mário de Andrade, quadros de Tarsila do Amaral - A negra, Abaporu, Antropofagia - na poesia pau-brasil de Oswald de Andrade, na de Raul Bopp, Murilo Mendes, e, mais tarde, de Carlos Drummond de Andrade, percebe-se a formulação da pergunta sobre a identidade nacional. Na década de 30, a construção de "imagens do Brasil" será a motivação dos primeiros grandes livros de interpretação do país: Casa Grande e Senzala, de Gilberto Freire; Raízes do Brasil, de Sérgio Buarque de Holanda e Formação do Brasil Contemporâneo de Caio Prado Júnior. Nos artistas, críticos e historiadores desse tempo flagra-se, se não a carência de identidade, pelo menos o mal-estar provocado pelo hibridismo e sincretismo cultural do país.

A busca de brasilidade no modernismo aparece não só como desejo de suprir a carência de identidade, mas também como resistência e reação à demanda europeia de exotismo. Assim, inventar o Brasil é reinventar a origem, negando aquela gerada pela colonização. A consciência da identidade como falta manifestava-se no modernismo mais radical, na antropofagia de Oswald de Andrade e na pintura de Tarsila do Amaral, em que a invenção aparece na composição da originalidade nativa com a cultura técnica, interessando-se menos pelo primitivismo exaltado pelos artistas europeus que pelo primitivismo enquanto volta ao "sentido puro" e à "inocência construtiva" da arte. ${ }^{2}$ Para Mário de Andrade, entretanto, a falta deveria ser suprida por um trabalho de formação, espécie de ideal que funcionaria como orientação na passagem do mimetismo à criação. Tratar-se-ia, para ele, de reatualizar a consciência artística em relação aos movimentos artístico-culturais europeus, compondo as raízes populares com a forma culta - tal como propõe no 
3. Ronaldo Brito. "A Semana de 22: o trauma do moderno". In S. Tolipan (org.). Sete ensaios sobre o modernismo. Rio de Janeiro: Funarte, 1983, p. 17 (Caderno de Textos 3).

4. Idem, Ibidem, p. 14; 16.

5. Sônia Salzstein. “O moderno como problema”. Jornal de Resenhas 29. Discurso Editorial/USP/Unesp/Folha de S.Paulo, 09/08/97, p. 8.
Ensaio sobre a música brasileira de 1928, nos estudos do folclore, das danças, das falas e de outras manifestações culturais populares de várias regiões do país.

Contudo, se de um lado a ênfase modernista na vinculação do moderno ao nacional constitui-se em alternativa construtiva, caracterizando uma atitude intelectual de conhecimento crítico do Brasil, e solução dos hibridismos e misturas, de outro, apresentou uma face oposta: a do nacionalismo conservador, de direita, de exaltação patrioteira, disfarce ideológico de uma visão mistificada da "originalidade brasileira" - aliás, um fato que volta e meia é reposto, às vezes na chave da mistificação.

O modernismo dos anos 20 foi a "primeira estratégia cultural moderna brasileira (...) menos pelas importantes marcas de linguagem que fixou - com as pinturas de Lasar Segall, Tarsila e Anita Malfatti e as esculturas de Brecheret - e mais, muito mais, pela própria dinâmica de sua operação cultural, suas conquistas, seus impasses, suas limitações". ${ }^{3}$ Exatamente porque foi uma intervenção numa realidade cultural que, embora atrasada em relação ao compasso da história europeia, poderia ser alvo de um trabalho de construção singularizada, não se pode reduzir o modernismo brasileiro a simples imitação ou transposição das modas artísticas europeias. Estava, sim, vinculando aos modelos culturais dominantes que deveriam ser conhecidos, assimilados naquilo que importava para efeitos de emancipação artístico-cultural, e o resto simplesmente descartado, conforme explicitado na visceral ironia da teoria antropofágica de Oswald de Andrade. $\mathrm{Na}$ guerra tardia contra o academismo, o modernismo vai desenvolver-se marcado por ambiguidades e inadequações, fato, aliás, persistente em toda trajetória de constituição da modernidade artística, cultural e sociopolítica no Brasil. Diferentemente das vanguardas europeias, que para afastar-se da tradição dissolviam as identidades, os modernistas assumiam e positivavam as condições e características locais, o hibridismo cultural e do olhar - uma espécie de "compulsão de conciliar e misturar". O cubismo que Tarsila mobilizava para pintar o Brasil, por exemplo, é estratégico: "formular uma percepção moderna brasileira". Aquilo que pareceria uma limitação, dela e de Anita - o primado do tema - era, na verdade um modo de "projetar o Brasil". 4

Como conciliar as aspirações modernas da arte brasileira da década de 20, seu lado experimental e investigativo, com o nacionalismo e o interesse pela cultura popular, já que estes são, geralmente, reivindicações conservadoras? Neste sentido, o moderno é um problema, pelo menos nos desenvolvimentos que vão das presenças inaugurais de Anita Malfatti, Tarsila do Amaral e Lasar Segall até a fixação da pintura de Cândido Portinari e Di Cavalcanti como emblemas de modernidade artística brasileira nos anos 30-40, época do segundo modernismo. ${ }^{5}$

As experiências de Tarsila, pela radicalidade do seu desejo de afirmação de uma pintura nacional através de soluções formais, e não apenas, temáticas - soluções buscadas na vertente construtivista da arte moderna e articulada aos signos e processos da sociedade industrial - escancaram as ambiguidades do encontro cultural. Daí vem a tensão interna de sua obra, a novidade de seu estilo. Já na pintura de Di Cavalcanti “a aspiração moderna da obra aparecerá o tempo todo refreada pela demanda de uma temática nacional e popular (...). Movida mais por sentimento de acomodação que de mudança, ela tentaria uma espécie de atualização 
6. Idem. "uma tensa celebração da modernidade". Folha de S.Paulo, Mais!, 07/09/97, p. 08.

7. Benedito Nunes. Oswald Canibal. São Paulo: Perspectiva, 1979, p.28.

8. Luiz Costa Lima. Pensando nos trópicos. Rio de Janeiro: Rocco, 1991, p. 27Ss. 'negociada' da arte brasileira”, com que Di “assegurava a assimilação frouxa, mas contínua, de um vocabulário moderno à arte brasileira, no curso de pelo menos três décadas de lenta atualização de nosso ambiente artístico, dos anos 20 aos 50", quando se dá a conquista do espaço moderno no Brasil. ${ }^{6}$

Entre 22 e 28 o modernismo produziu uma certa descontinuidade no ambiente cultural, culminando com a antropofagia de Oswald de Andrade, a pintura de Tarsila e o romance-rapsódia de Mário de Andrade, Macunaíma, em que se notam tentativas radicais de ajustar a experiência brasileira da vida com a tradição herdada. Na teoria antropofágica, assim como na poesia e prosa cubista de Oswald de Andrade, no livro de Mário e na pintura de Tarsila, encontra-se afirmada uma ideia de ruptura artístico-cultural que não estava clara nos inícios do modernismo, a não ser como aspiração de liberdade de criação e de atualização estética amalgamados ao desejo de ter, de inventar, uma cultura e uma arte nacionais.

Oswald de Andrade, nos manifestos Pau Brasil (1924) e Antropófago (1928), enfatiza uma espécie de "força primitiva de resistência à doutrinação promovida pelo colonizador". Assim, o "primitivismo da forma pura" é um princípio de sua poesia, de seus romances-invenção e da pintura de Tarsila que deriva da assimilação produtiva da diferença - "só me interessa o que não é meu. Lei do homem. Lei do antropófago". O primitivismo é "um princípio ativo da vida intelectual brasileira".7 Primitivo não é, pois, algo como uma utopia rousseauista, uma entidade primitiva, uma origem. Oswald de Andrade fala de um traço cultural, e não de um traço étnico. Essa capacidade de resistência "é identificada apenas pelo modo como opera; pelo canibalismo simbólico". Neste, o ajustamento cultural implica o conflito, pois a inclusão do "estrangeiro" pelo "primitivo" não elimina nem um nem outro; antes, o "valor prévio permanece e continua a circular em um novo corpo". ${ }^{8}$ Neste sentido, a antropofagia oswaldiana funcionou como ruptura no processo brasileiro de internalização dos valores ocidentais; de atualização artística e elaboração cultural. O conflito entre vanguarda europeia e modernismo brasileiro não se resolve por subsunção de um ao outro, nem por uma pseudo-dialética: tratava-se de sustentar as tensões entre a capacidade local de canibalizar as informações da cultura europeia sem sublimação dos antagonismos - ou seja, das descontinuidades entre os valores da sociedade brasileira e os valores ocidentais. A antropofagia explora o mal-estar na cultura, evidenciando aquilo que isto implica de conflito, tensão, luta. A "transformação permanente do tabu em totem", conforme se lê no Manifesto Antropófago, deve ser entendida como transformação do interdito em ritual de incorporação, "metamorfose do símbolo de excludente em includente". 9

A questão da dívida da antropofagia de Oswald de Andrade para com o canibalismo europeu é controversa; mas parece certo que o exotismo etnográfico dos canibalistas europeus não afetou a teoria oswaldiana. Oswald devorou-o. Tratando desse problema, Antonio Candido disse que as experiências modernistas eram "congeniais" àquelas da vanguarda francesa, reafirmando o que Oswald de Andrade dissera do primitivismo: foi "o único achado da geração de 22". ${ }^{10}$ Para Antonio Candido, "no Brasil as culturas primitivas se misturam à vida cotidiana ou são reminiscências ainda vivas de um passado recente. As terríveis ousadias de um Picasso, um Brancusi, um Max Jacob, um Tristan Tzara eram, no fundo, mais coerentes com a nossa herança cultural do que com a deles (...). Os nossos modernistas se informaram pois rapidamente da arte europeia de vanguarda, 
11. Antonio Candido. Literatura e Sociedade. $3^{\mathrm{a}}$.ed., São Paulo: Nacional, 1973, p. 121.

12. Idem. Vários escritos. $3^{\mathrm{a}}$.ed., São Paulo: Duas cidades, 1970, p. 85-86.

13. Cf. Mário Pedrosa. "Brasília, a cidade nova". In Aracy Amaral (Org.) Dos murais de Portinari aos espaços de Brasília. São Paulo: Perspectiva, 1981, p. 347 (Debates-170). aprenderam a psicanálise e plasmaram um tipo ao mesmo tempo local e universal de expressão, reencontrando a influência européia por um mergulho no detalhe brasileiro. É impressionante a concordância com que um Apollinaire e um Cendrars ressurgem, por exemplo, em Oswald de Andrade". ${ }^{11}$

No modernismo de Oswald de Andrade e de Mário de Andrade, no lirismo telúrico dos quadros de Tarsila e em aspectos da poesia de Manuel Bandeira e Raul Bopp teria havido a conjugação de componentes de vanguarda europeia com componentes recalcados da nacionalidade, na tentativa de pesquisar e exprimir a forma do país. Humor, ironia, uso de procedimentos paródicos e alegóricos, servem para experimentações em que a ousadia formal expunha dados etnográficos, elementos recalcados da experiência histórica da dominação - uma espécie de protesto cultural irreverente, anarco-primitivista. Um "estilo moderno brasileiro" delineia-se, pelo menos na literatura e um pouco na pintura, na descrição modernista, particularmente antropofágica, do choque de culturas. Em Macunaíma, diz Antonio Candido, "não apenas pela exploração do mundo primitivo, mas pela escavação do subsolo da cultura urbana, reinterpretando-a em termos primitivos. Em Serafim [Ponte Grande], pelo tratamento do homem urbano brasileiro como uma espécie de primitivo da era técnica, que afinal se dissolve no mito (...) Oswald explode o núcleo do nosso universo sincrético e dispõe os cacos numa admirável fantasmagoria do real". ${ }^{12}$ Devoração e mobilidade são os dois princípios da operação antropofágica: triturar, absorver e recompor os fragmentos de fatos, valores, símbolos da cultura dominada do passado colonial e da cultura de um presente em transformação sob o impacto da técnica e da industrialização modernas. Eis aí o lugar onde se funda a criatividade e a resistência cultural no Brasil, e que hoje se encontra deslocada.

O modernismo havia gerado e disseminado os signos inaugurais da modernidade brasileira, que se tornara um verdadeiro imperativo, impulsionando a criação artístico-cultural, aos ensinamentos decorrentes do encontro cultural, iniciando a exploração produtiva e construtivista dos conceitos, processos e procedimentos que gerariam um singular desejo de modernidade, em que as variáveis delineadas no modernismo desdobrariam tensões até virulentas. São estas as variáveis: ímpeto experimental, necessidade de conhecer o Brasil, portanto, nacionalismo e resolução dos problemas colocados pela intersecção, de sobreposição ou de mistura, dos dados da cultura européia, tradicional e moderna, da penetração das informações da cultura norte-americana, da elaboração dos elementos e signos populares, segundo a baliza, régua e compasso das culturais aqui em desenvolvimento, em especial dos dados da negritude.

Embora na década de 30, com a rotinização do modernismo, tivesse ocorrido o início do necessário e urgente processo de institucionalização dos signos de modernidade, em termos de política, cultura, educação e arte, principalmente sob a égide do ministério Capanema, nos quadros paradoxais do regime forte do Estado Novo - sem dúvida um marco incontornável do desatamento da modernização do país - é só de meados dos anos 50 aos anos 60 que se institui um projeto moderno no Brasil: um projeto construtivo brasileiro, respondendo à demanda tão bem formulada por Mário Pedrosa em 1959: o Brasil é um país condenado ao moderno. ${ }^{13}$ 
14. Cf. a propósito do tropicalismo, nosso livro Tropicália: alegoria, alegria (1979). $4^{\mathrm{a}}$.ed., São Paulo-Cotia: Ateliê Editorial, 2008.
É neste período que a par do desenvolvimentismo econômico-social e seus desdobramentos institucionais, ocorrem projetos e práticas que aos poucos articulam o desejo de conhecer o país. Na produção artístico-cultural, o experimentalismo é valorizado em todas as áreas, e a variável já enfatizada pelo modernismo, a cultura popular, vai adquirir contornos conceituais e práticos, aliando interesses sociopolíticos e práticas artístico-culturais. É neste quadro que os dados da integração da diversidade cultural na sociedade brasileira emergem em toda sua criatividade; através de ativações diversas de ordem étnica, pela valorização dos específicos elementos das manifestações folclóricas e populares da música, da dança, da cozinha, da rítmica religiosa etc. Na revisão cultural que se processou nos anos 60, o tropicalismo produziu uma modalidade de inserção histórica sui generis, ao construir uma linguagem de mistura em que são atualizados os temas básicos da revisão cultural: redescoberta do Brasil, volta às origens nacionais, internacionalização da cultura, dependência econômica, consumo e conscientização. Nesța mistura, as proposições da antropofagia oswaldiana pela primeira vez assumem concretude e efeitos: a mistura ou fusão da floresta e da escola, com a exclusão das "sublimações antagônicas". Frente ao clima de polarizações ideológicas a que o tema do encontro cultural chegara, oscilando entre a ênfase nas raízes nacionais e a importação cultural, a ideia oswaldiana de devoração cultural foi reapresentada como forma de relativização dessas posições. Um dos aspectos mais expressivos do primitivismo antropofágico que o tropicalismo retém é a concepção cultural sincrética e não tanto a sua dimensão etnográfica e a tendência em conciliar as culturas em conflito. Constrói um painel em que o universo sincrético, mistura de materiais arcaicos e modernos, se apresenta sob a forma de um presente contraditório, explodindo o universo monolítico das interpretações nacionalistas.O tropicalismo foi, assim, o momento terminal de inserção dos imperativos básicos da modernidade evidenciados no modernismo. ${ }^{14}$

No final dos anos 50 e inícios dos 60, e durante toda esta década, é possível identificar, principalmente agora, com a devida dịstância histórica, a inscrição concreta daqueles signos de modernidade, em que a cultura das diferenças e a criatividade multifacetada se evidenciam com força. Mais precisamente: a confluência de tradições culturais brasileira - em que a criatividade que avultava no sincretismo vinha sendo decantada e assimilada, sobretudo a partir do romantismo do século XIX, e trazida à tona enfaticamente por alguns modernistas - com a modernidade europeia e com os dados da cultura de massa norte-americana é toda tensionada pela emergência de um protagonista e mediador essencial, que funcionou como um verdadeiro conceito operacional e arma hermenêutica do debate e da atividade artístico-cultural do período: a cultura popular, principalmente a proveniente das experiências das culturas negras.

O que se quer evidenciar, portanto, é o elemènto gerador de um poder dè irradiação, propiciador da faculdade de detonar cruzamentos, misturas e superação de polarizações, passando do dado básico do sincrético às singularizações. Do emergente cinema novo ao tropicalismo do final da década, percebe-se a presença irradiadora dessa criatividade popular, a força dos signos que irradia e sua contribuição para a formulação de linguagens aptas para deslocar as antigas e já desgastadas posições sobre a relação experimentalismo-nacionalismo, vale dizer, sobre as linguagens oficiais instituintes das concepções culturais e imagens do 
Brasil. A extraordinária floração criativa dos anos 6o, toda ela direta ou indiretamente respondendo, num único movimento, ao imperativo da modernização e modernidade - parte em conformidade aos cálculos do regime militar e parte em resposta a eles -, deu a medida de um tempo das ilusões em que se tentou com fervor a ideia de emancipação fundada no ímpeto revolucionário singularizado em uma experiência cultural moderna brasileira.

O inventário das proposições e realizações daquele tempo permite destacar a importância do tema da cultura popular e de sua especificidade enquanto operador conceitual de um modo de intervenção nos debates e na produção artístico-cultural que retirou a discussão do plano de uma simples valorização das diversidades culturais das classificações étnicas ou das análises sociopolíticas da exclusão. Cultura popular funcionava como pura positividade, mesmo levando-se em conta as distinções que tentavam dar conta da amplidão do conceito. Por exemplo: a distinção que o projeto do CPC da UNE, formulado no início dos anos 6o, fazia entre cultura popular, cultura do povo e cultura popular evolucionária explicita a complexidade do problema durante toda a década de 60. Para fins de instrumentalização política, o CPC postulava uma concepção de arte que visava, por meio dos processos centrados nos efeitos catárticos de adesão emotiva dos receptores articulados pela técnica de denúncia das injustiças e exortação à ação, o efeito de conscientização do povo - este, uma categoria social abstrata, emblematizava imagens totalizadoras do cinema, do teatro, da poesia, da música.

No período entre o golpe de 64 e o AI-5 de 1968, a produção artístico-cultural, ainda que redimensionando as discussões, deslocando a ênfase da destinação de seus discursos da totalidade genérica "povo" para a fração, também com certa generalidade, de setores das classes médias, especialmente estudantes e intelectuais, continuou a centrar no conceito operacional de cultura popular, agora mais flexível, parte significativa de seus discursos e estratégias artístico-culturais na elaboração de crítica e resistência ao regime de exceção. As duas direções que se cristalizaram na época, gerando atitudes e debates polarizadores, entre a arte participante, "de protesto" e a arte experimental - que apesar de criticada pela primeira direção como alienada, na verdade também foi participante -, trabalharam com signos, processos e linguagens das culturas populares; agora cruzadas ou fundidas explicitamente às informações das comunicações de massa e das artes de vanguarda, especialmente as detonadas pela cultura pop norte-americana.

É preciso acentuar este dado brasileiro. Na diversidade das direções críticocriativas delineadas durante toda a década, é perceptível que a força do popular força a forma, força a experimentação, seja pela apropriação direta seja por apropriações e estilizações sofisticadas e herméticas dos dados e da criatividade do popular. Para efeito de exemplificação, pode-se citar alguns casos emblemáticos: as apropriações do popular feitas por Glauber Rocha em Barravento, Deus e o diabo na terra do sol e em Terra em transe; as proposições de Hélio Oiticica na teoria do parangolé e na construtividade popular das ambientações como tropicália; os espetáculos de Augusto Boal no Teatro de Arena, em Arena conta Bahia e Arena conta Tiradentes; os usos feitos por Caetano Veloso, Gilberto Gil, Torquato Neto e Capinam de temas e procedimentos musicais baianos e nordestinos; as referências das ilustrações de cordel misturadas aos quadrinhos e procedimentos pop por vários artistas plásticos. As proposições tropicalistas, patentes nas canções, assim como no 
15. Cf. Hélio Oiticica. Aspiro ao grande labirinto. Orgs. Luciano Figueiredo, Lygia Pape e Waly Salomão. Rio de Janeiro: Rocco, 1986. Cf. para a análise do trabalho de HO, nosso livro $A$ invenção de Hélio Oiticica (1992). $2^{\mathrm{a}}$ ed. São Paulo: Edusp, 2000. trabalho de Hélio Oiticica a partir da eclosão do "parangolé”, nas quais as discussões sobre o sincretismo cultural, a mistura de elementos culturais e processos artísticos de proveniência diversa atingem o limite crítico e expressivo do período, são significativas da posição central da criatividade popular na produção artísticocultural do período recortado.

É o caso, exemplar, do trabalho de Hélio Oiticica. Nele, o dado popular aparece associado ao deslocamento do tema da criação configurado na tradição ocidental, como critério para propor uma concepção de um além-da-arte centrado na imagem de criação coletiva, emblematizada em uma determinada experiências popular, a da música e dança do samba e a da construtividade popular do morro da Mangueira. É a proposta de participação coletiva, interessada tanto na superação da arte, que é desintegrada e reconceituada, como no redimensionamento cultural dos protagonistas, pela integração do coletivo, que mobiliza os artistas. Seu campo de ação não é apenas o sistema de arte, mas a visionária atividade coletiva que intercepta subjetividade e significação social. A "antiarte", proposta com que Oiticica pretende radicalizar a situação da arte transformando os participantes, "proporcionando-lhes proposições abertas ao seu exercício imaginativo", visando a "desalienar o indivíduo" para "torná-lo objetivo em seu comportamento éticosocial”. Apontando para uma outra inscrição do estético, Oiticica visualiza a arte como intervenção cultural e o artista como "motivador para a criação". ${ }^{15}$

O imaginário de Oiticica é aquele que se interessa, não pelos simbolismos da arte, mas pela função simbólica das atividades, cuja densidade teórica está na suplantação da pura imaginação pessoal em favor de um "imaginativo" coletivo. Isto se cumpre quando as atividades possuem visão crítica na identificação de práticas culturais com poder de transgressão; não pela simples figuração das indeterminações e conflitos sociais, ou, ainda, pela denúncia da alienação dos discursos sobre a realidade brasileira. A participação coletiva provém da abertura das proposições; evita as circunscrições habituais da arte e o puro exercício espontaneísta de uma suposta criatividade generalizada. Para Oiticica, a antiarte é a "verdadeira ligação definitiva entre manifestação criativa e coletividade", tem poder de transgressão, identificando-se a práticas e revoltas "contra valores e padrões estabelecidos", desde os mais socialmente organizada até as mais viscerais e individuais. A conexão entre o coletivo e o individual, experiência de inconformismo social que ultrapassa o mero interesse por mitos, valores e formas de expressão das vivências populares, leva Oiticica a uma marginalidade nada circunstancial. Da Mangueira, Oiticica apropriou-se do samba, que manifesta uma "força mítica interna, individual e coletiva"; da arquitetura das favelas, com suas casas bricoladas e das relações sociais do povo da Mangueira, em que Oiticica surpreende uma ética comunitária. Signo de transformabilidade, para ele a experiência da dança, a "descoberta do corpo" pelo samba, converge com as da abertura estrutural e da incorporação da cor na eclosão da proposição do parangolé com que dão salto para um além da pintura, respondendo à "necessidade vital de desintelectualização, de desinibição intelectual, à necessidade de uma livre expressão". Foi o samba que, inicialmente, lhe possibilitou a transformação de sua concepção artística, pela imersão no ritmo e no gesto; mais tarde viu no rock possibilidades ainda mais livre de expressão do corpo. 
O destaque do samba e do rock nas manifestações e projetos ambientais de Oiticica liga-se à posição da música popular, como prática cultural que incide sobre as potências do corpo, como reflexão sobre o cotidiano e como produção que expõe ambiguidades e contradições sociais. Neste sentido, a música tropicalista abriu um campo experimental inédito nos domínios da canção praticada no Brasil. Explorando a estrutura híbrida e imprecisa da canção, recarregou a música popular: texto, melodia, ritmo, vocalização, arranjo, gestualidade e dança nela são redimensionados e se entre-exprimem. Articulando elementos diversos - tradição musical brasileira, rock, iê-iê-iê, música experimental, poesia de vanguarda, enquadramentos e montagens cinematográficos - explodiu os limites que determinavam a música popular, problematizando-a como gênero artístico, forma de comunicação, crítica e comercial, e enquanto manifestação popular.

A valorização que Oiticica faz da produção musical do grupo baiano é consequência da sua percepção de que coincidia com o sentido de suas proposições ambientais. De qualquer maneira, sabe-se que os músicos foram denominados "tropicalistas" porque o seu modo de atuação foi julgado semelhante ao que ocorria no projeto ambiental Tropicália, que Oiticica instalara no MAM do Rio de Janeiro em 1967, simultaneamente à eclosão das primeiras músicas tropicalistas de Caetano e Gil. Sabe-se também que a música Tropicália de Caetano Veloso foi assim denominada por admitir semelhanças temáticas e estruturais com o ambiente de Oiticica.

No artigo "O sentido de vanguarda do grupo baiano", ${ }^{16}$ Oiticica ressaltou a coincidência de proposta, de procedimentos e de crítica cultural entre o seu programa ambiental e a produção do grupo baiano. Detectou nos tropicalistas uma posição revolucionária no processo de revisão cultural por meio da renovação das artes no Brasil, pois estavam sintonizados com os "problemas universais da vanguarda”, manifestando em suas atividades visão estrutural e radicalidade crítica. Em Tropicália - um labirinto feito de dois penetráveis, plantas, areias, araras, poemas-objeto, capas-parangolé, aparelhos de TV, música, dança - monta-se uma cena que mistura o "tropical", referido a primitivo, mágico e popular, com mensagens e imagens tecnológicas, proporcionando experiências visuais, táteis, sonoras; brincadeiras e caminhadas. Penetrando no ambiente, o participante envolve-se com materiais e referências culturais disparatados; devorando imagens, entra numa atividade que provoca a reflexão, pois não se apresenta aí qualquer síntese possível dessa mistura de elementos contraditórios. A convergência dos projetos de Oiticica e dos tropicalistas patenteia-se, portanto, na transformação do espectador ou ouvinte em protagonista de ações, pela exploração da indeterminação provocada pela abertura estrutural e do heteróclito de materiais e referências agenciados nos sistemas.

A rememoração destes projetos e produções, do modernismo à tropicália, a parece aqui como uma perspectiva de pensamento interessado na elaboração de experiências criativas de resistência à integração indiferenciada da lógica cultural estabelecida com a universalização radical do mercado. E, voltando à frase emblemática de Machado de Assis, repropor a pergunta, para sondar os signos que aquelas propostas inscreveram. Parece claro que hoje estas imagens de resistência 
estão desatualizadas e mesmo inviabilizadas, pois típicas de um tempo de promessas, de crença nas possibilidades abertas de ruptura social e no poder transformador da cultura e das artes. Contudo, considerando que os princípios modernos ainda são ativos, como repontecializá-los segundo as condições atuais da cultura e das artes? Então, de que modo a arte ainda poderia resistir a alguma coisa? A questão implica, talvez, a reelaboração daquela dimensão estética da experiência contemporânea, ainda interessada na reconfiguração dos termos da emancipação. 